\title{
Transition Specific Risk Factors Affecting the Lifestyle Disease Progression from Diabetes to Hypertension in India
}

\author{
Wahengbam Bigyananda Meitei1, Laishram Ladusingh² \\ ${ }^{1}$ International Institute for Population Sciences, Mumbai, India \\ ${ }^{2}$ Bodoland University, Assam, India \\ Email: bigyan030294@gmail.com
}

How to cite this paper: Meitei, W.B. and Ladusingh, L. (2019) Transition Specific Risk Factors Affecting the Lifestyle Disease Progression from Diabetes to Hypertension in India. Health, 11, 1055-1071. https://doi.org/10.4236/health.2019.118083

Received: July 8, 2019

Accepted: August 13, 2019

Published: August 16, 2019

Copyright ( 2019 by author(s) and Scientific Research Publishing Inc. This work is licensed under the Creative Commons Attribution International License (CC BY 4.0).

http://creativecommons.org/licenses/by/4.0/ (c) (i) Open Access

\begin{abstract}
Diabetes and hypertension are common co-morbid associates and coexist in many of the cases. The study attempts to understand the two-way transition between diabetes and hypertension and the risk factors affecting the transition using the multistate model. The study used data from the first and second waves of IHDS. There is a significant rise in the level of diabetes and hypertension from 2004-05 to 2011-12. Except for transition from hypertension to diabetes, the probability of transition in all other transition decreases and the mean waiting time to stay in the healthy state increases after adjusting for several covariates. Increases in the level of smoking, drinking of alcohol, consumption of tobacco, body mass index, education and household income quintile are the major transition specific risk factors affecting the transition between diabetes and hypertension. And the risk of transitioning from a healthy state to hypertension is higher among females compared to males.
\end{abstract}

\section{Keywords}

Diabetes, Hypertension, Transition, Disease Progression, India

\section{Introduction}

The burden of diabetes and hypertension is fast increasing across the globe and is considered as the major risk factors of coronary artery disease (CAD), cardiovascular and cerebrovascular diseases (CVDs) [1] [2]. They are also the risk factors of dementia at old age [3]. Epidemiological, clinical and basic science studies have also documented a significant association between diabetes and cataract [4] [5] [6] [7]. The aetiology of diabetes is both genetic and environ- 
mental including lifestyle changes and limited physical activities. The burden of diabetes in India by 2030 is predicted to be 79.4 million individuals while that for China is 42.3 million and the United States 30.3 million [8]. India is also dubiously known as the world's capital of diabetes from the fact that every fifth Indian is diabetic [9]. High blood pressure is another leading cause of non-communicable diseases. WHO estimated that by 2025 the global burden of hypertension would be 1.56 billion, increase of 60 percent and for India in 2000, individuals with hypertension were estimated as 60.4 million males and 57.8 million females and projected to increase to 107.3 million and 106.2 million respectively in 2025 [10]. Raised blood pressure is the risk factor of a host of diseases. Individuals with high blood pressure are twice more likely to developed CAD, four times higher risk of congestive heart failure and associated risk of CVDs and compared to normotensive individuals, stroke is seven times higher among hypertensive individuals [11].

Diabetes and hypertension are common co-morbid associates and coexist in approximately 40 to 60 percent of patients [12]. The most disturbing scenario of these diseases in India is the shift in age of onset of diabetes to a younger age and trickling down to rural areas in the recent years [13]. In early stage both these diseases do not show any symptoms and go unnoticed to many of the victims of these diseases. Steps to reorient public health programmes emphasizing on prevention and early detection of diabetes and hypertension from early age can pave way to reduce the burden of non-communicable diseases. Under the supervision of Indian Council of Medical Research (ICMR), a study on diabetes called "INdia DIABetes (INDIAB)" study was initiated and estimated the prevalence of diabetes as 10.4 percent in Tamil Nadu, 8.4 percent in Maharashtra, 5.3 percent in Jharkhand and 13.6 percent in Chandigarh [14]. The overall number of people with diabetes mellitus in India in 2011 based on the same study was estimated to be 62.4 million. Various studies estimated the prevalence of hypertension among urban population ranging from 1.24 percent in 1949 to 36.4 percent in 2003 and for rural people from 1.99 percent in 1958 to 21.2 percent in 1994 [15]. Recent studies have shown that hypertension is present in 25 percent of urban and 10 percent of rural subjects in India [16].

In a vast country like India, there is considerable regional variation in the prevalence of non-communicable diseases (NCD), due to fast changing food and lifestyle morbidities pattern and its associated risk factors. Further it is also to be noted that there is dearth of study on associated risk factors of NCD based on morbidity assessment of individuals over time. Therefore, it is also the necessity of repeated assessment of morbidities of same individuals over time to identify the inter-relationship between diabetes and hypertension due to its coexistence in many of the cases. Keeping this in view in this paper an attempt is made to understand the two-way transition between diabetes and hypertension and the risk factors affecting the transition using multistate model. The other accompanying objective of the study is to provide an assessment of the increase in the 
prevalence of diabetes and hypertension in India. The cases of diabetes and hypertension considered in this study are cases diagnosed by physician and not reported cases.

\section{Methods and Materials}

\subsection{Data}

This is a community-based study using panel data from the first and second wave of the India Human Development Survey [IHDS-I (2004-05) \& IHDS-II (2011-12)]. IHDS is a nationally representative survey covering multiple topics of public health and community basic amenities. Both waves of IHDS were jointly conducted by researchers from the University of Maryland, USA and the National Council of Applied Economic Research (NCAER), New Delhi (https://www.ihds.umd.edu/). The design of IHDS is a panel survey where 41,554 households in 1503 villages and 971 urban neighborhood were interviewed on two occasions, first in 2004-05 and then for the second time in 2011-12. Data used in the study consists of 148,333 individuals of all ages followed from 2004-05 to 2011-12.

\subsection{Outcome \& Predictor Variables}

Respondents in the first wave (2004-05) were followed up and the same information on their health and morbidities were reassessed again in the second wave (2011-12). The respondents were asked if the doctor had diagnosed them for diabetes and hypertension. Based on their response, a respondent is identified as having diabetes or hypertension or free from these diseases. Diabetes and hypertension are the lifestyle diseases which can be catastrophic to one's livelihood to a great extent. Behavioural risk factors such as smoking, drinking, consumption of tobacco and sedentary habits have been proved to increase the risk of diabetes and hypertensions [17] [18] [19]. Other physical, social and economic conditions are also found to be significant prognosticators of this lifestyle disease [20] [21] [22]. Besides behavioural risk factors, the study also considers sex, place of residence, level of education, body mass index and income quintile of the household as the prognosticators of the transition from diabetes to hypertension and vice-versa.

\subsection{Statistical Analysis}

Multistate models are often used to describe the progression of diseases [23]-[28]. The multistate model explains how an individual changes its states between a series of states in continuous time. The study considers three states of transition viz. healthy (0), diabetes (1) and hypertension (3) having the state space $S(t)=\{0,1,2\}$. We assume the probability of transition from state of diabetes to healthy $(1-0)$ and from state of hypertension to healthy $(2-0)$ is zero as there is no complete cure to diabetes and hypertension rather than controlling its intensity of burden. Figure 1 shows the path of transition between the three states. 
Figure 2 shows the transition in the state space $S(t)$ at different waves of IHDS. Of all 148,333 respondents who entered in the first wave of IHDS, 224 respondents were diagnosed as having suffered from diabetes and 448 were diagnosed as having suffered from hypertension. Among those who were not diagnosed to be either diabetic or hypertensive in first wave of IHDS, 1468 respondents develop diabetes and 3876 develop hypertension. Among those 224 respondents who were diagnosed as diabetic, 26 respondents develop hypertension. And among those 448 respondents who were diagnosed with hypertension, 58 respondents develop diabetes.

The respondents in the study move through the state space $S(t)=\{0,1,2\}$ which is governed by the transition intensity, $q_{i j}(t, a(t)) ; i, j=0,1,2$. Transition intensities are the instantaneous risk of moving from state $i$ to $j$ defined as

$$
q_{i j}(t, a(t))=\lim _{\delta t \rightarrow 0} \frac{P[S(t+\delta t)=j \mid S(t)=i]}{\delta t}
$$

Such that the $3 \times 3$ transition intensity matrix is, $Q=\left[\begin{array}{lll}q_{00} & q_{01} & q_{02} \\ q_{10} & q_{11} & q_{12} \\ q_{20} & q_{21} & q_{22}\end{array}\right]$

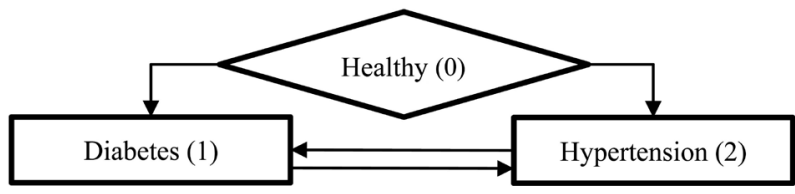

Figure 1. Paths of transition between healthy, diabetes and hypertension.

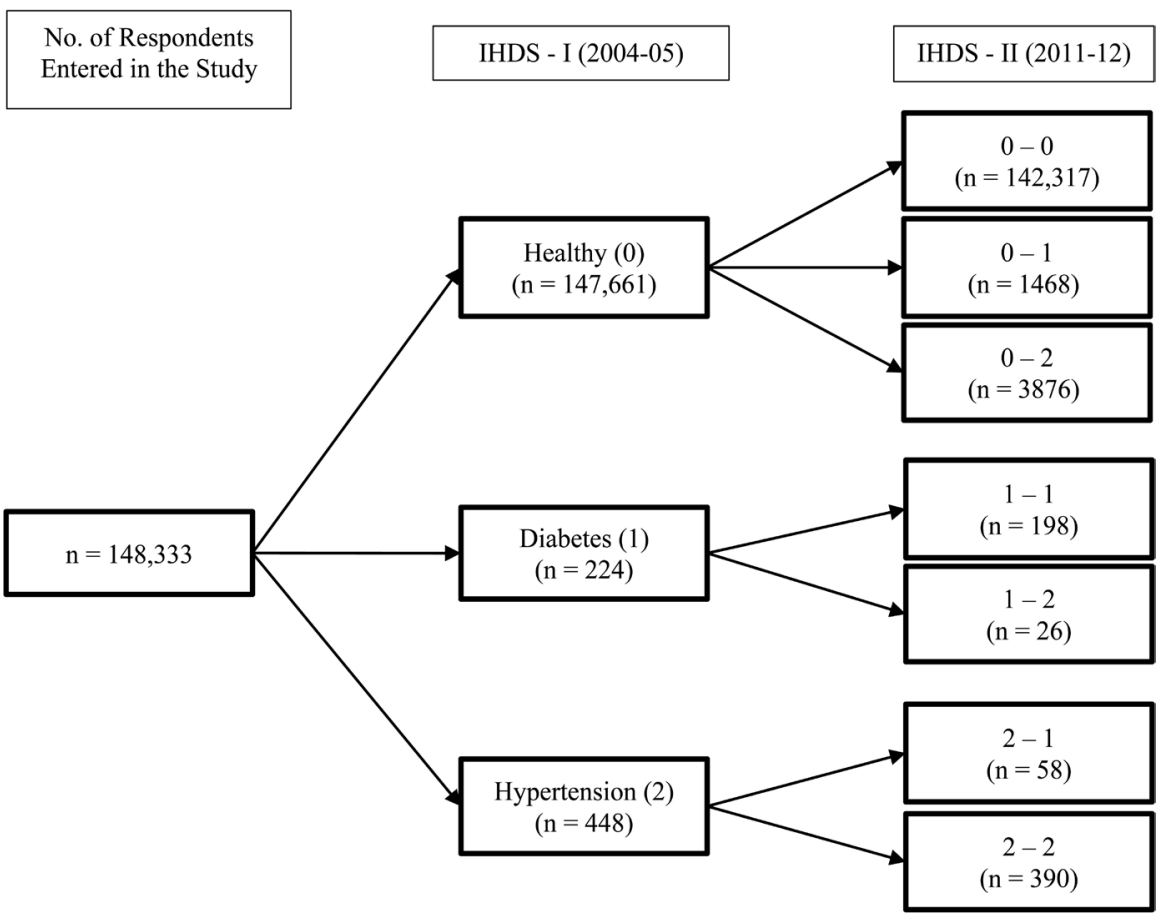

Figure 2. Flow chart displaying the transition in the state space $S(t)$ at different waves of India human development survey. 
where $\sum_{j}^{3} q_{i j}=0$.

Multistate model generally depends on Markov assumption that future movement to next state $j$ depends on the current state $i$ [29].

In a time homogeneous Markov model, where $q_{i j}$ are independent of $t$, the mean waiting time in each state $i$ is exponentially distributed with mean $-1 / q_{i j}$. And the likelihood for the Markov model is calculated from the transition probability matrix, $P(x, t+x)$. The $(i, j)$ entry of $P(x, t+x)$ is the probability of being in state $j$ at time $t+u$, given the state at time $u$ is $i$. This matrix is calculated in terms of $Q$ using Kolmogorov differential equations. If $Q$ is constant over the interval $(x, t+x)$ as in a time homogeneous process, then $P(x, t+x)=P(t)$ and the equation is solved by the matrix exponential of $Q$ scaled by the time interval,

$$
P(t)=\operatorname{Exp}(t Q)
$$

We used "msm" package in R-Software to produce the desired outputs. The package "msm" was specifically developed to model the progression of diseases [30]. It allows time homogeneous Markov models to be fitted to processes like that of disease progression which can be observed continuously. In a multistate model, the relationship between the time-varying characteristics of individuals to their transition probabilities or intensities is of vital importance. Thus a form of a proportional hazard model was developed to describe this relationship [25]. The package also allows us to model the relationship between individual specific or time dependent characteristics with transition intensities [30]. It also allows us to estimate the transition probabilities, the probability that each state is next and the mean waiting time.

\section{Results}

Table 1 presents the percentage distribution of 148,333 respondents included in the study by their socioeconomic and demographic backgrounds for two waves of IHDS. The proportion of respondents who had never taken alcohol and never consumed tobacco have declined over time from 2004-05 to 2011-12. Whereas the proportion of respondents who had never smoked increases over time. No appreciable and little change is noticed in distribution of respondents by sex, place of residence and income quintile between the surveys. But there is an increase in the proportion of respondents whose body mass index is greater than 24.9. Similarly, the respondent's level of education also increases between the surveys.

\subsection{Change in the Distributions of Diabetes and Hypertension from 2004-05 to 2011-12}

Table 2 and Table 3 present the unadjusted assessment of prevalence of diabetes and hypertension respectively from both waves of the IHDS. Compared to the first wave of IHDS in 2004-05, the prevalence of diabetes and hypertension 
Table 1. Percentage distribution of sampled respondents by socioeconomic and demographics in two occasions, 2004-05 and 2011-12.

\begin{tabular}{|c|c|c|c|c|}
\hline & \multicolumn{2}{|c|}{ IHDS I (2004-05) } & \multicolumn{2}{|c|}{ IHDS II (2011-12) } \\
\hline & $\mathbf{N}$ & $\%$ & $\mathbf{N}$ & $\%$ \\
\hline \multicolumn{5}{|c|}{ Behavioral Characteristics } \\
\hline \multicolumn{5}{|c|}{ Status of Drinking Alcohol } \\
\hline Never & 140,998 & 95.06 & 137,676 & 92.82 \\
\hline Not Frequent & 5326 & 3.59 & 8554 & 5.77 \\
\hline Frequent & 2009 & 1.35 & 2103 & 1.42 \\
\hline \multicolumn{5}{|c|}{ Status of Tobacco Consumption } \\
\hline Never & 133,767 & 90.18 & 128,646 & 86.73 \\
\hline Not Frequent & 2086 & 1.41 & 2897 & 1.95 \\
\hline Frequent & 12,480 & 8.41 & 16790 & 11.32 \\
\hline \multicolumn{5}{|l|}{ Status of Smoking } \\
\hline Never & 134,573 & 90.72 & 142767 & 96.25 \\
\hline Not Frequent & 2561 & 1.73 & 3565 & 2.40 \\
\hline Frequent & 11,199 & 7.55 & 2001 & 1.35 \\
\hline \multicolumn{5}{|c|}{ Individual Characteristics } \\
\hline \multicolumn{5}{|l|}{$\operatorname{Sex}$} \\
\hline Male & 77,929 & 52.54 & 77,968 & 52.56 \\
\hline Female & 70,404 & 47.46 & 70,365 & 47.44 \\
\hline \multicolumn{5}{|l|}{ Level of Education } \\
\hline Illiterate & 59,626 & 40.20 & 38,645 & 26.05 \\
\hline Primary & 35,152 & 23.70 & 34,386 & 23.18 \\
\hline Secondary & 47,028 & 31.70 & 63,687 & 42.94 \\
\hline Higher Education & 6527 & 4.40 & 11,615 & 7.83 \\
\hline \multicolumn{5}{|l|}{ Body Mass Index } \\
\hline Less than 18.5 & 77,712 & 52.39 & 57,271 & 38.61 \\
\hline 18.5 to 24.9 & 54,216 & 36.55 & 67,803 & 45.71 \\
\hline 24.9 \& Above & 16,405 & 11.06 & 23,259 & 15.68 \\
\hline \multicolumn{5}{|l|}{ Place of Residence } \\
\hline Rural & 104,486 & 70.44 & 101,096 & 68.15 \\
\hline Urban & 43,847 & 29.56 & 47,237 & 31.85 \\
\hline \multicolumn{5}{|c|}{ Household Characteristics } \\
\hline \multicolumn{5}{|l|}{ Income Quintile } \\
\hline Lowest Income & 25,069 & 16.90 & 25,285 & 17.05 \\
\hline Lower Income & 25,664 & 17.30 & 28,775 & 19.40 \\
\hline Middle Income & 28,571 & 19.26 & 30,083 & 20.28 \\
\hline Higher Income & 32,750 & 22.08 & 31,501 & 21.24 \\
\hline Highest Income & 36,276 & 24.46 & 32,689 & 22.04 \\
\hline Total & 148,333 & 100.00 & 148,333 & 100.00 \\
\hline
\end{tabular}

Source: Authors computation from Indian human development survey. 
Table 2. Prevalence of Diabetes (per 1000) in two waves of India Human Development Survey (2004-05, 2011-12).

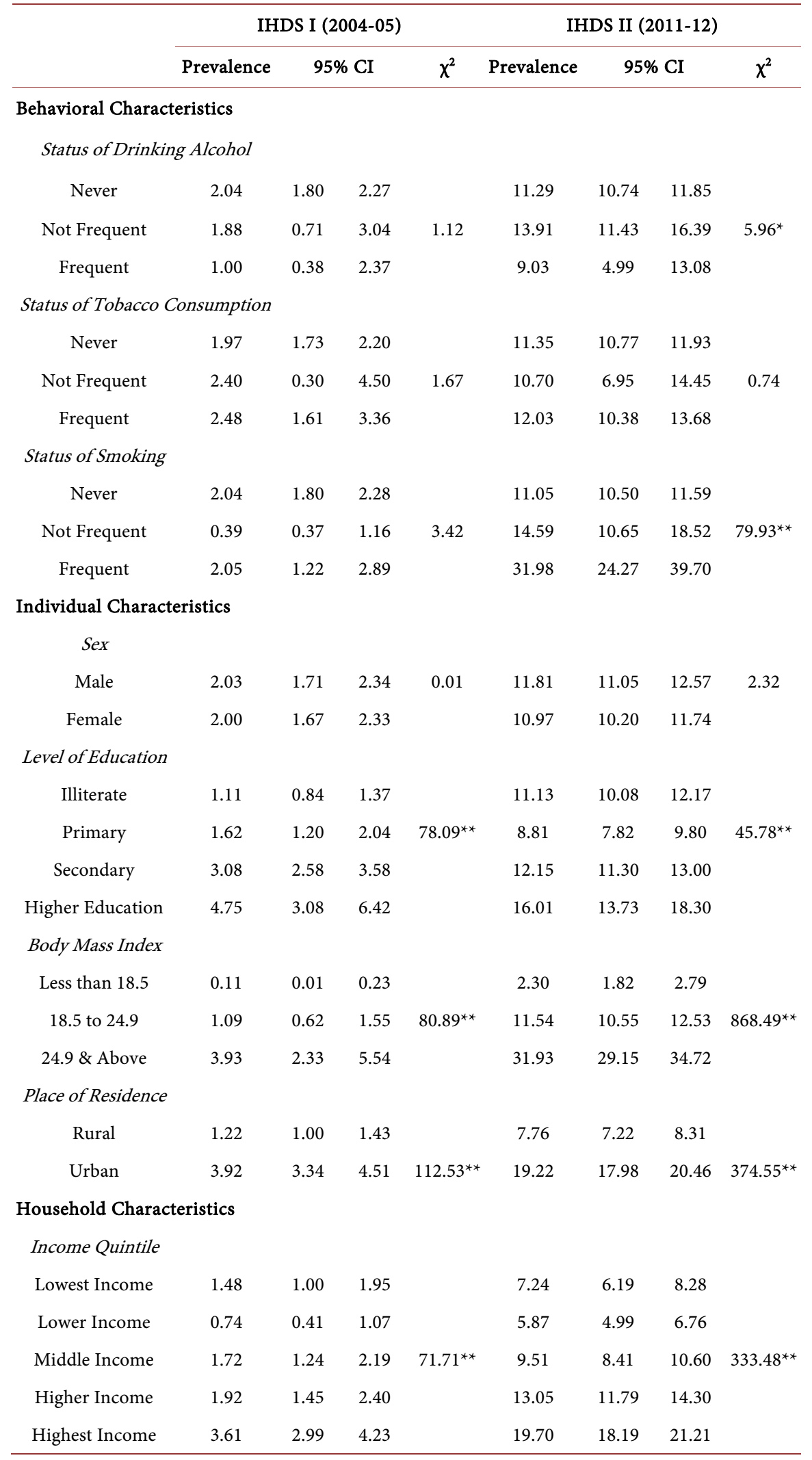

Note: ${ }^{* *} \mathrm{p}$-value $<0.01 \&{ }^{\star} \mathrm{p}$-value $<0.05 ; \mathrm{CI}-$ Confidence Interval. 
Table 3. Prevalence of Hypertension (per 1000) in two waves of India Human Development Survey (2004-05, 2011-12).

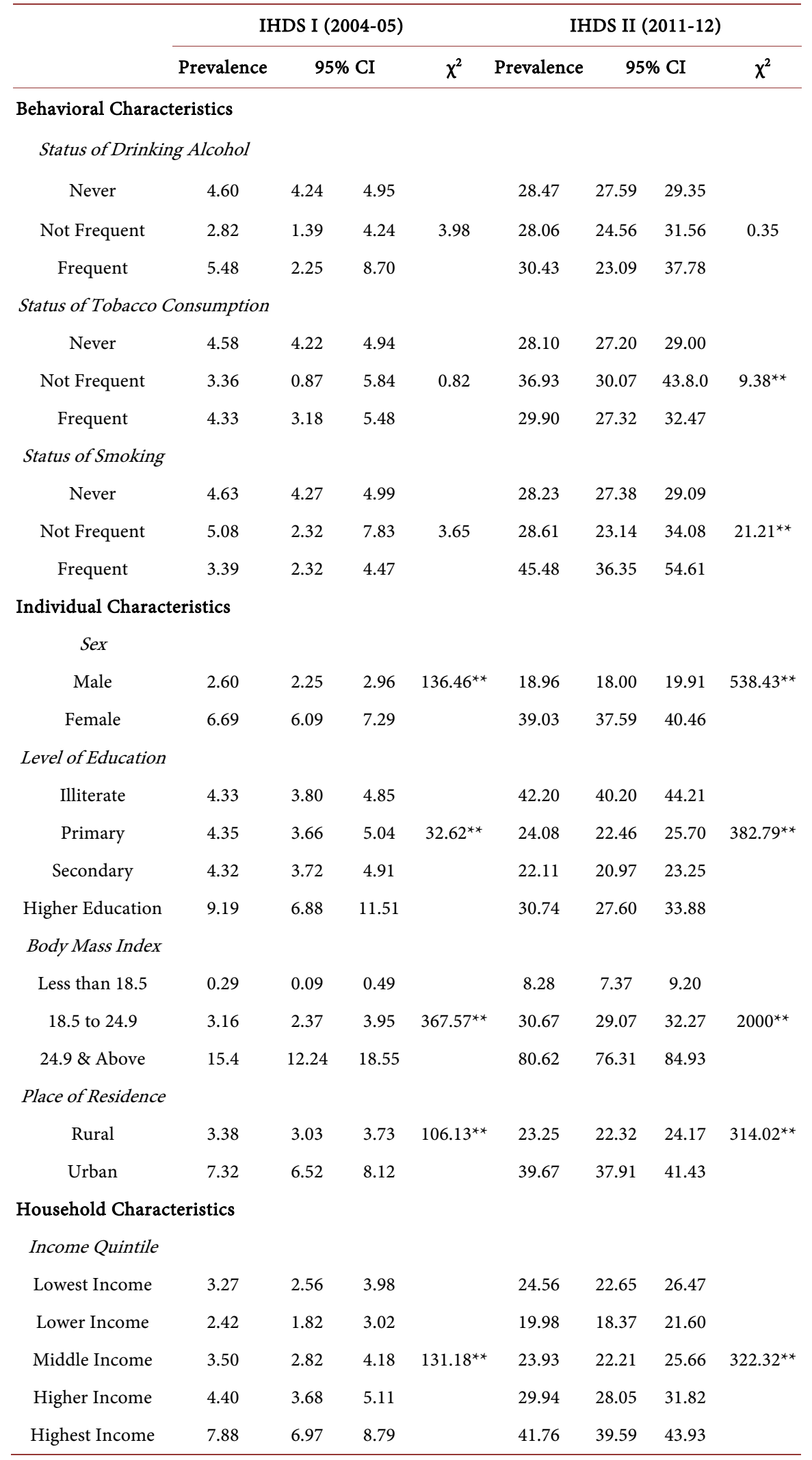

Note: ${ }^{* *} \mathrm{p}$-value $<0.01 \&{ }^{\star}$ p-value $<0.05 ; \mathrm{CI}-$ Confidence Interval. 
increased in the second wave in 2011-12. The behavioral risk factors viz. smoking, drinking and chewing tobacco does not show statistically significant association with these lifestyle diseases in the first wave. But, there is an evidence of strong association in the second wave. Comparatively those respondents who drink, smoke and consume tobacco frequently have the higher prevalence of diabetes and hypertension. The prevalence of diabetes in the second wave who drink, consume tobacco and smoke frequently are 9.03, 12.03 and 31.98 per one thousand respectively. Whereas the prevalence of hypertension in the second wave who drink, consume tobacco and smoke frequently are 30.43, 29.90 and 45.48 per one thousand respectively. Sex is not showing significant association with diabetes. But a strong association can be seen between sex and hypertension. The prevalence of hypertension in first wave for males and females are 2.60 and 6.69 per one thousand respectively. And the prevalence of hypertension in second waves for males and females are 18.96 and 39.03 per one thousand respectively. The association between respondent place of residence, level of education, body mass index and income quintile of the household with diabetes and hypertension is highly statistically significant. The prevalence of diabetes and hypertension is higher among urban residents as compared to rural residents. The prevalence of diabetes in rural and urban place of residence in second wave are 7.76 and 19.22 per one thousand respectively. Similarly, the prevalence of hypertension in rural and urban place of residence are 23.25 and 39.65 per one thousand respectively. The prevalence of diabetes and hypertension increases as the level of education increases in the first wave. But the pattern is not the same in the second wave. The prevalence of diabetes in second wave among the illiterates and respondents who have attained primary, secondary and higher education are $11.13,8.81,12.15$ and 16.01 per one thousand respectively. Similarly, the prevalence of hypertension in second waves among illiterates and respondents who have attained primary, secondary and higher education are 42.20, 24.08, 22.11 and 30.74 per one thousand respectively. In both waves of IHDS, the prevalence of diabetes and hypertension increases as the level of body mass index and the income quintile of the household increase. The prevalence of diabetes and hypertension among the respondents with body mass index greater than 24.9 in second wave are 31.93 and 80.62 per one thousand respectively. While the prevalence of diabetes among the lowest, lower, middle, higher and highest income quintile household in second wave are 7.24, 5.87, 9.51, 13.05 and 19.70 per one thousand respectively. And the prevalence of hypertension among the lowest, lower, middle, higher and highest income quintile household in second wave are $24.56,19.98,23.93,29.94$ and 41.76 per one thousand respectively.

\subsection{Transition Probabilities}

Table 4 gives the unadjusted and adjusted fitted transition probability in transitioning from one state to other over the time interval, 2004-05 to 2011-12. The unadjusted probability to remain in a healthy state during the interval is 0.964 
compared to the adjusted probability of 0.971 . It also gives us the probability of 0.010 and 0.026 , for an individual who are currently healthy will be diabetic and hypertensive respectively. Whereas the probability that an individual who is currently healthy will be diabetic and hypertensive after adjusting for several covariates are 0.007 and 0.022 respectively. Also the probability that an individual who is diabetic will be hypertensive and vice versa are 0.058 and 0.044 respectively compared to 0.024 and 0.024 respectively after adjusting for several covariates.

\subsection{Mean Waiting Time}

Table 5 gives the unadjusted and adjusted mean waiting time for the three state of transition. The unadjusted waiting time to remain in the healthy state, diabetic state and hypertensive state are 27.13 years $(95 \% \mathrm{CI}=[26.41,27.87]), 16.23$ years $(95 \% \mathrm{CI}=[5.09,11.07])$ and 21.8 years $(95 \% \mathrm{CI}=[5.18,8.74])$ respectively. Whereas the mean waiting time after adjusting for several covariates to remain in the healthy state, diabetic state and hypertensive state are 32.23 years $(95 \% \mathrm{CI}=[32.60,36.43]), 39.90$ years $(95 \% \mathrm{CI}=[2.82,20.52])$ and 40.77 years $(95 \% \mathrm{CI}=[3.52,7.45])$ respectively.

\subsection{Transition Specific Risk Factors of Transition between Diabetes and Hypertension}

Table 6 presents the transition specific hazard ratio of different socioeconomic and demographic characteristics on different paths of transition. Compared to respondents who never drink alcohol, respondents who drink alcohol but not

Table 4. Estimated transition probabilities while moving through the state space, $S(t)=\{0,1,2\}$.

\begin{tabular}{cccccccc}
\hline & \multicolumn{3}{c}{ Unadjusted } & & \multicolumn{3}{c}{ Adjusted $^{*}$} \\
\hline & State 0 & State 1 & State 2 & & State 0 & State 1 & State 2 \\
\hline State 0 & 0.964 & 0.010 & 0.026 & State 0 & 0.971 & 0.007 & 0.022 \\
State 1 & 0 & 0.884 & 0.116 & State 1 & 0 & 0.888 & 0.112 \\
State 2 & 0 & 0.129 & 0.871 & State 2 & 0 & 0.167 & 0.833 \\
\hline
\end{tabular}

Note: "Adjusting for several behavioral, individual and household level characteristics. State 0: Healthy; State 1: Diabetes \& State 2: Hypertension.

Table 5. Mean waiting time in the transient states and their confidence intervals.

\begin{tabular}{cccccccc}
\hline \multicolumn{3}{c}{ Unadjusted } & \multicolumn{3}{c}{ Adjusted $^{*}$} \\
\hline & Estimate & \multicolumn{2}{c}{$95 \%$ CI } & & Estimate & \multicolumn{2}{c}{$95 \%$ CI } \\
\hline State 0 & 27.13 & 26.41 & 27.87 & State 0 & 34.46 & 32.60 & 36.43 \\
State 1 & 7.51 & 5.09 & 11.07 & State 1 & 7.60 & 2.82 & 20.52 \\
State 2 & 6.73 & 5.18 & 8.74 & State 2 & 5.12 & 3.52 & 7.45 \\
\hline
\end{tabular}

Note: ${ }^{*}$ Adjusting for several behavioral, individual and household level characteristics. State 0: Healthy; State 1: Diabetes \& State 2: Hypertension. 
Table 6. Transition specific hazard ratios of different socioeconomic and demographic characteristics on different path of transition.

\begin{tabular}{llllllllll}
\hline & \multicolumn{3}{c}{$0-1$} & & $0-2$ & & $1-2$ & & $2-1$ \\
\cline { 2 - 6 } & HR & $95 \% \mathrm{CI}$ & HR & $95 \% \mathrm{CI}$ & HR & $95 \% \mathrm{CI}$ & HR & $95 \% \mathrm{CI}$ \\
\hline
\end{tabular}

\section{Behavioral Characteristics}

Status of Drinking Alcohol

Never $^{\circledR}$

$\begin{array}{ccccccccccccc}\text { Not Frequent } & 2.42^{* *} & 1.49 & 3.94 & 0.76 & 0.54 & 1.08 & 4.56^{* *} & 1.73 & 12.02 & 0.66 & 0.25 & 1.76 \\ \text { Frequent } & 2.41 & 0.82 & 7.08 & 0.71 & 0.34 & 1.46 & 9.85^{* *} & 2.35 & 41.22 & 1.17 & 0.21 & 6.52\end{array}$

Status of Tobacco Consumption

Never ${ }^{\circledR}$

$\begin{array}{ccccccccccccc}\text { Not Frequent } & 0.31 & 0.05 & 1.97 & 2.11^{* *} & 1.62 & 2.76 & 0.05 & 0.00 & 1.90 & 2.59^{* *} & 1.38 & 4.85 \\ \text { Frequent } & 0.91 & 0.56 & 1.50 & 1.78^{* *} & 1.51 & 2.10 & 0.71 & 0.31 & 1.62 & 1.02 & 0.54 & 1.92\end{array}$

Status of Smoking

Never $^{\circledR}$

$\begin{array}{ccccccccccccc}\text { Not Frequent } & 1.77^{* *} & 1.03 & 3.04 & 1.93^{* *} & 1.39 & 2.68 & 0.75 & 0.22 & 2.61 & 1.30 & 0.56 & 3.02 \\ \text { Frequent } & 1.31 & 0.83 & 2.06 & 2.31^{* *} & 1.94 & 2.74 & 0.24 & 0.02 & 2.38 & 1.08 & 0.53 & 2.21\end{array}$

Individual Characteristics

Sex

Female

$0.98 \quad 2.59^{* *}$

$2.28 \quad 2.93$

0.66

0.30

1.42

0.93

$0.59 \quad 1.47$

Level of Education

Illiterate ${ }^{\circledR}$

Primary

Secondary

Higher Education

Body Mass Index

Less than $18.5^{\circledR}$

$\begin{array}{lcccccccccccc}\text { Primary } & 1.43 & 0.80 & 2.56 & 0.84^{* *} & 0.75 & 0.95 & 1.90 & 0.59 & 6.06 & 1.01 & 0.59 & 1.71 \\ \text { Secondary } & 3.08^{* *} & 1.86 & 5.11 & 1.03 & 0.92 & 1.15 & 1.91 & 0.65 & 5.62 & 0.79 & 0.47 & 1.32 \\ \text { igher Education } & 5.93^{* *} & 3.42 & 10.28 & 1.01 & 0.75 & 1.36 & 4.70^{* *} & 1.48 & 14.91 & 0.25^{* *} & 0.08 & 0.83 \\ \begin{array}{l}\text { Body Mass Index } \\ \text { Less than } 18.5^{\circledR}\end{array} & & & & & & & & & & & & \\ 18.5 \text { to } 24.9 & & & & & & & & & & & & \\ 24.9 \text { \& Above } & 0.94 & 0.63 & 1.40 & 1.13^{* *} & 1.02 & 1.25 & 0.56 & 0.16 & 1.94 & 0.39^{* *} & 0.18 & 0.82 \\ & 1.66 & 0.95 & 2.91 & 2.12^{* *} & 1.82 & 2.47 & 0.24 & 0.03 & 1.72 & 0.97 & 0.54 & 1.75\end{array}$

Place of Residence

$$
\begin{aligned}
& \text { Rural }^{\circledR} \\
& \text { Urban }
\end{aligned}
$$

Income Quintile

Lowest Income ${ }^{\circledR}$

Lower Income

$\begin{array}{cccccccccccc}1.19 & 0.76 & 1.87 & 0.74^{* *} & 0.64 & 0.85 & 0.53 & 0.06 & 4.68 & 0.44 & 0.16 & 1.22 \\ 1.00 & 0.63 & 1.58 & 0.99 & 0.87 & 1.13 & 1.16 & 0.31 & 4.30 & 1.43 & 0.83 & 2.48 \\ 1.59^{* *} & 1.05 & 2.41 & 1.19^{* *} & 1.06 & 1.36 & 1.51 & 0.54 & 4.22 & 1.33 & 0.77 & 2.30 \\ 1.89^{* *} & 1.18 & 3.05 & 1.52^{* *} & 1.32 & 1.74 & 1.54 & 0.53 & 4.53 & 1.53 & 0.89 & 2.64\end{array}$

Note: ${ }^{* *}$ p-value $<0.01 \&{ }^{*}$ p-value $<0.05$; HR: Hazard Ratio; CI: Confidence Interval. Transition from healthy to diabetes $(0-1)$; Transition from healthy to hypertension (0 - 2); Transition from diabetes to hypertension (1 - 2); Transition from hypertension to diabetes $(2-1)$. 
frequently are more likely to have diabetes $(\mathrm{HR}=2.42 ; 95 \% \mathrm{CI}=[1.49,3.94])$. While among the respondents who are diabetic, respondents who drink alcohol but not frequently $(\mathrm{HR}=4.56 ; 95 \% \mathrm{CI}=[1.73,12.02])$ and who drink alcohol frequently $(\mathrm{HR}=9.85 ; 95 \% \mathrm{CI}=[2.35,41.22])$ are more likely to have hypertension. Similarly, compared to respondents who had never consumed tobacco, respondents who consumed tobacco but not frequently $(\mathrm{HR}=2.11 ; 95 \% \mathrm{CI}=$ $[1.62,2.76])$ and who consumed tobacco frequently $(\mathrm{HR}=1.78 ; 95 \% \mathrm{CI}=[1.51$, 2.10]) are more likely to have hypertension. Among those who are hypertensive, respondents who consumed tobacco but not frequently are more likely to have diabetes $(\mathrm{HR}=2.59 ; 95 \% \mathrm{CI}=[1.38,4.85])$. Compared to respondents who had never smoked, respondents who smoked but not frequently are more likely to have diabetes $(\mathrm{HR}=1.77 ; 95 \% \mathrm{CI}=[1.03,3.04])$. While respondents who smoked but not frequently $(\mathrm{HR}=1.93 ; 95 \% \mathrm{CI}=[1.39,2.68])$ and respondents who smoked frequently $(\mathrm{HR}=2.31 ; 95 \% \mathrm{CI}=[1.94,2.74])$ are more likely to have hypertension. Sex of the respondents is also significantly associated with transition from healthy state to diabetic state and hypertensive state. Compared to male, female are less likely to suffer from diabetes ( $\mathrm{HR}=0.72 ; 95 \% \mathrm{CI}=[0.52$, $0.98])$ but more likely to suffer from hypertension ( $\mathrm{HR}=2.59 ; 95 \% \mathrm{CI}=[2.28$, 2.93]). Compared to illiterate respondents, respondents who have attained secondary $(\mathrm{HR}=3.08 ; 95 \% \mathrm{CI}=[1.86,5.11])$ and higher education $(\mathrm{HR}=5.93$; $95 \% \mathrm{CI}=[3.42,10.28])$ are more likely to have diabetes. Also respondents who are diabetic and have attained higher education are more likely to have hypertension $(\mathrm{HR}=4.70 ; 95 \% \mathrm{CI}=[1.48,14.91])$. But respondents who have attained primary education are less likely to have hypertension compared to illiterate respondents $(\mathrm{HR}=0.84 ; 95 \% \mathrm{CI}=[0.75,0.95])$. Similarly respondents who are hypertensive and have attained higher education are less likely to have diabetes $(\mathrm{HR}=0.25 ; 95 \% \mathrm{CI}=[0.08,0.83])$. Compared to respondents with body mass index less than 18.5, respondents having higher body mass index are more likely to have hypertension. But, respondents who are hypertensive and having body mass index 18.5 to 24.9 are less likely to have diabetes $(\mathrm{HR}=0.39 ; 95 \% \mathrm{CI}=$ $[0.18,0.82])$. Respondents living in urban are more likely to suffer from diabetes $(\mathrm{HR}=2.16 ; 95 \% \mathrm{CI}=[1.70,2.75])$ and hypertension $(\mathrm{HR}=1.26 ; 95 \% \mathrm{CI}=[1.15$, 1.38]) than those living in rural areas. Compared to respondents from household with lowest income quintile, respondents from household with higher income quintile $(\mathrm{HR}=1.59 ; 95 \% \mathrm{CI}=[1.05,2.41])$ and highest income quintile $(\mathrm{HR}=$ $1.89 ; 95 \% \mathrm{CI}=[1.18,3.05])$ are more likely to suffer from diabetes. Similarly, respondents from household with higher income quintile $(\mathrm{HR}=1.19 ; 95 \% \mathrm{CI}=$ $[1.06,1.36])$ and highest income quintile $(\mathrm{HR}=1.52$; $95 \% \mathrm{CI}=[1.32,1.74])$ are more likely to suffer hypertension.

\section{Discussion}

The sustainable burden of diabetes and hypertension is on the rise in India [31]. They are the leading cause of CAD and CVDs and also the major co-morbid conditions contributing highly to the burden of non-communicable diseases 
[32]. The associations between these two lifestyle diseases embark considerable interest worldwide. Diabetes and hypertension are one of the most prevalent chronic diseases and a major public health problem in India with its prevalence rapidly increasing in both urban and rural populations [33] [34]. The study highlights the significant increase in the prevalence of diabetes and hypertension in India from 2004-05 to 2011-12. The prevalence of diabetes and hypertension are on a rise in both rural and urban place of residence and in both males and females. And the prevalence of hypertension is comparatively higher in females than males. Similarly increase in the prevalence of these lifestyle diseases can be seen across all households with different levels of income quintile, individual's with different levels of educations and body mass index and across all levels of behavioral risk factors such as smoking, consumption of tobacco and drinking of alcohol.

There are several evidences to support the association between diabetes and hypertension. Compared to people without diabetes, the risk of developing coronary diseases is two to four time higher among people with diabetes [19]. And diabetes was almost two and half times more likely to develop among people with hypertension as in people with normal blood pressure [35] [36] [37]. Hyperinsulinsm and insulin resistance may lead to hypertension through altered intracellular calcium metabolism, which will enhance renal sodium reabsorption or through an effect of insulin upon lipid and catecholamine metabolism [38]. The United Kingdom Prospective Diabetes Study (UKPDS) and other study groups found each $10 \mathrm{mmHg}$ decrease in the mean systolic blood pressure was associated with reduction in risk of 12 percent for any complication related to diabetes mellitus and 15 percent for deaths related to diabetes mellitus [39] [40]. The above mentioned relationship between diabetes and hypertension are based on its prevalence. But, here in our study, a different approach was adopted to establish the relationship between diabetes and hypertension. We estimated the transition probability to quantify the relationship between diabetes and hypertension. Except for transition from hypertension to diabetes, the probability of transition decreases in all other transition after adjusting for several behavioral, individual and household level characteristics. Similarly, the mean waiting time to the healthy state increases while the mean waiting time to diabetes and hypertension decreases.

Tobacco use, unhealthy diet, harmful use of alcohol and physical inactivity are some of the main behavioral risk factors of these diseases [17] [18] [41] [42] [43]. Similarly, various other physical and socio-economic conditions play a significant role in increasing the risk of these lifestyle diseases [20] [21] [22]. Likewise, the study highlights the transition specific risk factors affecting the transition between diabetes and hypertension. Behavioral risk factor like drinking of alcohol significantly increases the risk of transitioning from healthy to the state of diabetes state and from the state of diabetes to the state of hypertension. While smoking significantly increases the risk of transitioning from healthy to both state of diabetes and hypertension. And consumption of tobacco is mainly 
associated with transition from healthy state to the state of hypertension and from the state of hypertension to the state of diabetes. The risk of transitioning from healthy state to the state of hypertension is higher among females than males. And the risk of transitioning from healthy state to the state of diabetes or hypertension and transitioning from diabetes to hypertension is higher among the urban areas than rural areas. Similarly, as the level of education, body mass index and household income quintile increases, the risk of transitioning between these lifestyle diseases increase.

Like the other study, the study does not simply consider the cases of diabetes and hypertension reported by the respondents. The study includes only those cases which have been diagnosed as having diabetes or hypertension by a physician. And this is the first ever study in India, attempting to establish the probability of transition between these lifestyle diseases and provide the transition specific risk factors. Despite this major strength of the study, it is also subject to the limitation of not able to include more waves for addressing the transition from diabetes to hypertension and vice-versa due to non-availability of further waves of IHDS. While previous study suggests the importance of inclusion of more waves to increase the statistical power [44].

\section{Conclusion}

The study highlights the rise in the level of diabetes and hypertension from 2004-05 to 2011-12. The transition probability for different transitions between diabetes and hypertension decreases and the mean waiting time of staying in healthy state increases after controlling for several behavioral, individual and household level characteristics. Increase in the level of smoking, drinking of alcohol, consumption of tobacco, body mass index, education and household income quintile are the major transition specific risk factors affecting the transition between diabetes and hypertension. And gender wise, the risk of transitioning from healthy state to hypertension is higher among females.

\section{Authors Contributions}

WBM conducted the analysis and prepared the first draft. LL conceived and designed the study.

\section{Ethical Statement}

Ethical consideration does not arise as the study used secondary data publicly available.

\section{Conflicts of Interest}

The authors declare no conflicts of interest regarding the publication of this paper.

\section{References}

[1] Qureshi, A.I., Suri, M.F.K., Kirmani, J.F., Divani, A.A. and Mohammad, Y. (2005) Is 
Prehypertension a Risk Factor for Cardiovascular Diseases? Stroke, 36, 1859-1863. https://doi.org/10.1161/01.STR.0000177495.45580.f1

[2] Wu, S., Huang, Z., Yang, X., Li, S., Zhao, H., Ruan, C., Wu, Y., Xin, A., Li, K., Jin, C. and Cai, J. (2013) Cardiovascular Events in a Prehypertensive Chinese Population: Four-Year Follow-Up Study. International Journal of Cardiology, 167, 2196-2199. https://doi.org/10.1016/j.ijcard.2012.05.123

[3] Raina, S.K., Chander, V., Raina, S., Kumar, D., Grover, A. and Bhardwaj, A. (2015) Hypertension and Diabetes as Risk Factors for Dementia: A Secondary Post-Hoc Analysis from North-West India. Annals of Indian Academy of Neurology, 18, 63.

[4] Nirmalan, P.K., Robin, A.L., Katz, J., Tielsch, J.M., Thulasiraj, R.D., Krishnadas, R. and Ramakrishnan, R. (2004) Risk Factors for Age Related Cataract in a Rural Population of Southern India: The Aravind Comprehensive Eye Study. British Journal of Ophthalmology, 88, 989-994. https://doi.org/10.1136/bjo.2003.038380

[5] Saxena, S., Mitchell, P. and Rochtchina, E. (2004) Five-Year Incidence of Cataract in Older Persons with Diabetes and Pre-Diabetes. Ophthalmic Epidemiology, 11, 271-277. https://doi.org/10.1080/09286580490510733

[6] Mukesh, B.N., Le, A., Dimitrov, P.N., Ahmed, S., Taylor, H.R. and McCarty, C.A. (2006) Development of Cataract and Associated Risk Factors: The Visual Impairment Project. Archives of Ophthalmology, 124, 79-85.

https://doi.org/10.1001/archopht.124.1.79

[7] Raman, R., Rani, P.K., Rachepalle, S.R., Gnanamoorthy, P., Uthra, S., Kumaramanickavel, G. and Sharma, T. (2009) Prevalence of Diabetic Retinopathy in India: Sankara Nethralaya Diabetic Retinopathy Epidemiology and Molecular Genetics Study Report 2. Ophthalmology, 116, 311-318. https://doi.org/10.1016/j.ophtha.2008.09.010

[8] Kumar, A., Goel, M.K., Jain, R.B., Khanna, P. and Chaudhary, V. (2013) India towards Diabetes Control: Key Issues. The Australasian Medical Journal, 6, 524. https://doi.org/10.4066/AMJ.2013.1791

[9] Joshi, S.R. and Parikh, R.M. (2007) India; the Diabetes Capital of the World: Now Heading towards Hypertension. Journal: Association of Physicians of India, 55, 323.

[10] Kearney, P.M., Whelton, M., Reynolds, K., Muntner, P., Whelton, P.K. and He, J. (2005) Global Burden of Hypertension: Analysis of Worldwide Data. The Lancet, 365, 217-223. https://doi.org/10.1016/S0140-6736(05)17741-1

[11] Lawes, C.M., Vander Hoorn, S., Law, M.R., Elliott, P., MacMahon, S. and Rodgers, A. (2006) Blood Pressure and the Global Burden of Disease 2000. Part 1: Estimates of Blood Pressure Levels. Journal of Hypertension, 24, 413-422. https://doi.org/10.1097/01.hjh.0000199801.72563.6f

[12] Arauz-Pacheco, C., Parrott, M.A. and Raskin, P. (2002) The Treatment of Hypertension in Adult Patients with Diabetes. Diabetes Care, 25, 134-147. https://doi.org/10.2337/diacare.25.1.134

[13] Mohan, V., Deepa, M., Deepa, R., Shanthirani, C.S., Farooq, S., Ganesan, A. and Datta, M. (2006) Secular Trends in the Prevalence of Diabetes and Impaired Glucose Tolerance in Urban South India-The Chennai Urban Rural Epidemiology Study (CURES-17). Diabetologia, 49, 1175-1178. https://doi.org/10.1007/s00125-006-0219-2

[14] Anjana, R.M., Pradeepa, R., Deepa, M., Datta, M., Sudha, V., Unnikrishnan, R., Bhansali, A., Joshi, S.R., Joshi, P.P., Yajnik, C.S. and Dhandhania, V.K. (2011) Prevalence of Diabetes and Prediabetes (Impaired Fasting Glucose and/or Impaired Glucose Tolerance) in Urban and Rural India: Phase I Results of the Indian Council 
of Medical Research India Diabetes (ICMR-INDIAB) Study. Diabetologia, 54, 3022-3027. https://doi.org/10.1007/s00125-011-2291-5

[15] Gupta, R. (2004) Trends in Hypertension Epidemiology in India. Journal of Human Hypertension, 78, 73-78. https://doi.org/10.1038/sj.jhh.1001633

[16] Gupta, R. (2016) Convergence in Urban-Rural Prevalence of Hypertension in India. Journal of Human Hypertension, 30, 79. https://doi.org/10.1038/jhh.2015.48

[17] Colditz, G.A., Willett, W.C., Rotnitzky, A. and Manson, J.E. (1995) Weight Gain as a Risk Factor for Clinical Diabetes Mellitus in Women. Annals of Internal Medicine, 122, 481-486. https://doi.org/10.7326/0003-4819-122-7-199504010-00001

[18] Hu, F.B., Manson, J.E., Stampfer, M.J., Colditz, G., Liu, S., Solomon, C.G. and Willett, W.C. (2001) Diet, Lifestyle, and the Risk of Type 2 Diabetes Mellitus in Women. New England Journal of Medicine, 345, 790-797. https://doi.org/10.1056/NEJMoa010492

[19] Kannel, W.B. and McGee, D.L. (1979) Diabetes and Cardiovascular Disease: The Framingham Study. JAMA, 241, 2035-2038. https://doi.org/10.1001/jama.1979.03290450033020

[20] American Diabetes Association (1998) Economic Consequences of Diabetes Mellitus in the US in 1997. Diabetes Care, 21, 296-309. https://doi.org/10.2337/diacare.21.2.296

[21] Arredondo, A. and Zúñiga, A. (2004) Economic Consequences of Epidemiological Changes in Diabetes in Middle-Income Countries: The Mexican Case. Diabetes Care, 27, 104-109. https://doi.org/10.2337/diacare.27.1.104

[22] Muszbek, N., Brixner, D., Benedict, A., Keskinaslan, A. and Khan, Z.M. (2008) The Economic Consequences of Noncompliance in Cardiovascular Disease and Related Conditions: A Literature Review. International Journal of Clinical Practice, 62, 338-351. https://doi.org/10.1111/j.1742-1241.2007.01683.x

[23] Longini Jr., I.M., Clark, W.S., Byers, R.H., Ward, J.W., Darrow, W.W., Lemp, G.F. and Hethcote, H.W. (1989) Statistical Analysis of the Stages of HIV Infection Using a Markov Model. Statistics in Medicine, 8, 831-843. https://doi.org/10.1002/sim.4780080708

[24] Gentleman, R.C., Lawless, J.F., Lindsey, J.C. and Yan, P. (1994) Multi-State Markov Models for Analysing Incomplete Disease History Data with Illustrations for HIV Disease. Statistics in Medicine, 13, 805-821. https://doi.org/10.1002/sim.4780130803

[25] Marshall, G. and Jones, R.H. (1995) Multi-State Models and Diabetic Retinopathy. Statistics in Medicine, 14, 1975-1983. https://doi.org/10.1002/sim.4780141804

[26] Satten, G.A. and Longini Jr., I.M. (1996) Markov Chains with Measurement Error: Estimating the "True" Course of a Marker of the Progression of Human Immunodeficiency Virus Disease. Journal of the Royal Statistical Society: Series C (Applied Statistics), 45, 275-295. https://doi.org/10.2307/2986089

[27] Andersen, P.K. (1988) Multistate Models in Survival Analysis: A Study of Nephropathy and Mortality in Diabetes. Statistics in Medicine, 7, 661-670.

https://doi.org/10.1002/sim.4780070605

[28] Guihenneuc-Jouyaux, C., Richardson, S. and Longini Jr., I.M. (2000) Modeling Markers of Disease Progression by a Hidden Markov Process: Application to Characterizing CD4 Cell Decline. Biometrics, 56, 733-741. https://doi.org/10.1111/j.0006-341X.2000.00733.x

[29] Cox, D.R. and Miller, H.D. (1965) The Theory of Stochastic Process. Chapman and Hall, London. 
[30] Jackson, C. (2007) Multi-State Modeling with R: The MSM Package. MRC Biostatistics Unit, Cambridge.

[31] Joshi, S.R., Saboo, B., Vadivale, M., Dani, S.I., Mithal, A., Kaul, U., Badgandi, M., Iyengar, S.S., Viswanathan, V., Sivakadaksham, N. and Chattopadhyaya, P.S. (2012) Prevalence of Diagnosed and Undiagnosed Diabetes and Hypertension in India-Results from the Screening India's Twin Epidemic (SITE) Study. Diabetes Technology and Therapeutics, 14, 8-15. https://doi.org/10.1089/dia.2011.0243

[32] Cheung, B.M. and Li, C. (2012) Diabetes and Hypertension: Is There a Common Metabolic Pathway? Current Atherosclerosis Reports, 14, 160-166. https://doi.org/10.1007/s11883-012-0227-2

[33] Gupta, R. and Guptha, S. (2010) Strategies for Initial Management of Hypertension. The Indian Journal of Medical Research, 132, 531.

[34] International Diabetes Federation (2015) International Diabetes Federation Diabetes Atlas. 7th Edition.

https://www.idf.org/e-library/epidemiology-research/diabetes-atlas/13-diabetes-atla s-seventh-edition.html

[35] Gress, T.W., Nieto, F.J., Shahar, E., Wofford, M.R. and Brancati, F.L. (2000) Hypertension and Antihypertensive Therapy as Risk Factors for Type 2 Diabetes Mellitus. New England Journal of Medicine, 342, 905-912. https://doi.org/10.1056/NEJM200003303421301

[36] Paul, B., Sapra, B., Maheshwari, S. and Goyal, R.K. (2000) Role of Losartan Therapy in the Management of Diabetic Hypertension. The Journal of the Association of Physicians of India, 48, 514-518.

[37] Lago, R.M., Singh, P.P. and Nesto, R.W. (2007) Diabetes and Hypertension. Nature Clinical Practice Endocrinology and Metabolism, 3, 667-668. https://doi.org/10.1038/ncpendmet0638

[38] Mahler, R.J. (1990) Diabetes and Hypertension. Hormone and Metabolic Research, 22, 599-607. https://doi.org/10.1055/s-2007-1004983

[39] WHO (1996) Hypertension Control: Report of a WHO Expert Committee.

[40] Mogensen, C.E. (1998) Combined High Blood Pressure and Glucose in Type 2 Diabetes: Double Jeopardy. British Medical Journal, 317, 693-695.

https://doi.org/10.1136/bmj.317.7160.693

[41] Knowler, W.C., Barrett-Connor, E., Fowler, S.E., Hamman, R.F., Lachin, J.M., Walker, E.A. and Nathan, D.M. (2002) Reduction in the Incidence of Type 2 Diabetes with Lifestyle Intervention or Metformin. The New England Journal of Medicine, 346, 393-403. https://doi.org/10.1056/NEJMoa012512

[42] WHO (2000) Global Strategy for the Prevention and Control of Non-Communicable Diseases.

[43] WHO (2009) Global Health Risks: Mortality and Burden of Disease Attributable to Selected Major Risks.

[44] Singer, J.D., Willett, J.B. and Willett, J.B. (2003) Applied Longitudinal Data Analysis: Modeling Change and Event Occurrence. Oxford University Press, Oxford. 